\title{
Effects of biomass smoke on pulmonary functions: a case control study
}

\author{
This article was published in the following Dove Press journal: \\ International Journal of COPD \\ 19 July 2016 \\ Number of times this article has been viewed
}

\author{
Baran Balcan' \\ Selcuk Akan² \\ Aylin Ozsancak Ugurlu' \\ Bahar Ozcelik Handemir ${ }^{3}$ \\ Berrin Bagcı Ceyhan ${ }^{4}$ \\ Sevket Ozkaya ${ }^{5}$ \\ 'Department of Pulmonary Medicine, \\ Baskent University Faculty of \\ Medicine, Istanbul, ${ }^{2}$ Department of \\ Internal Medicine, Ankara Education \\ and Teaching Hospital, Ankara, \\ ${ }^{3}$ Department of Pulmonary Medicine, \\ Irmet Hospital, ${ }^{4}$ Department of \\ Pulmonary Medicine, Marmara \\ University Faculty of Medicine, \\ ${ }^{5}$ Department of Pulmonary Medicine, \\ Faculty of Medicine, Bahcesehir \\ University, Istanbul, Turkey
}

Background: Biomass smoke is the leading cause of COPD in developing countries such as Turkey. In rural areas of Turkey, females are more exposed to biomass smoke because of traditional lifestyles.

Aim: The aim of this study was to determine the adverse effects of biomass smoke on pulmonary functions and define the relationship between duration in years and an index (cumulative exposure index) with altered pulmonary function test results.

Participants and methods: A total of 115 females who lived in the village of Kağizman (a borough of Kars located in the eastern part of Turkey) and were exposed to biomass smoke were included in the study. The control group was generated with 73 individuals living in the same area who were never exposed to biomass smoke.

Results: Twenty-seven (23.8\%) females in the study group and four (5.5\%) in the control group had small airway disease $(P=0.038)$. Twenty-two $(19.1 \%)$ females in the study group and ten $(13.7 \%)$ in the control group had obstruction $(P=0.223)$. Twenty $(17.3 \%)$ females in the study group who were exposed to biomass smoke had restriction compared with ten $(13 \%)$ in the control group $(P=0.189)$. The duration needed for the existence of small airway disease was 16 years, for obstructive airway disease was 17 years, and for restrictive airway disease was 17 years. The intensity of biomass smoke was defined in terms of cumulative exposure index; it was calculated by multiplying hours per day, weeks per month, and total years of smoke exposure and dividing the result by three.

Conclusion: Exposure to biomass smoke is a serious public health problem, especially in rural areas of developing countries, because of its negative effects on pulmonary functions. As the duration and the intensity of exposure increase, the probability of having altered pulmonary function test results is higher.

Keywords: biomass, exposure, pulmonary function, duration, intensity

\section{Introduction}

In the urban areas of developing countries such as Turkey, biomass (eg, wood, animal dung, crop residues) is used as a source of energy. ${ }^{1,2}$ Exposure to biomass smoke is the leading cause of COPD, especially in developing countries. ${ }^{3}$ A half of COPD deaths are due to biomass exposure, and 75\% of these deaths occur in females. ${ }^{3,4}$ Females are more exposed to biomass smoke than men in Turkey because of traditional lifestyles in rural areas. Carbon monoxide, nitrous oxide, sulfur oxide, formaldehyde, and polycyclic organic matter, including carcinogens such as benzopyrene, are all products of biomass smoke. ${ }^{5}$ These microparticulate products reach the peripheral airways and produce adverse effects on pulmonary functions. ${ }^{6}$ The primary aim of this study was to determine the difference of pulmonary functions between females who were exposed to biomass smoke and those who were not and the secondary aim was to determine the time course relationship with
Correspondence: Baran Balcan Department of Pulmonary Medicine, Baskent University Faculty of Medicine, 7 Oymaci Street, Istanbul 34662, Turkey Tel +90530 4l42308

$\mathrm{Fax}+90216554 \quad 1500$

Email drbaranbalcan@yahoo.com
International Journal of COPD 2016:1 I 1615-1622

1615

Dovepress f 5 in $\mathbf{0}$

http://dx.doi.org// 0.2147/COPD.S109056 (c) (1) (5) 2016 Balcan et al. This work is published and licensed by Dove Medical Press Limited. The full terms of this license are available at https://www.dovepress.com/terms.php

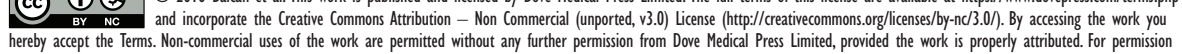
hereby accept the Terms. Non-commercial uses of the work are permitted without any further permission from Dove Medich
for commercial use of this work, please see paragraphs 4.2 and 5 of our Terms (https://www.dovepress.com/terms.php). 
altered pulmonary function test (PFT) results and define the importance of intensity of smoke on pulmonary functions, with the calculation of a new index (cumulative exposure index [CEI]), which has not been described in the literature before.

\section{Participants and methods}

There is a tradition in the village of Kağizman (a borough of Kars located in the eastern part of Turkey) that females are responsible for the cooking of bread in their houses. People are exposed to heavy smoke due to the cooking conditions (lack of chimney and poor ventilation; Figure 1). Girls start making bread at the age of 15 years, and the daily exposure to smoke is between 2 hours and 4 hours; they usually cook 1 day/wk, ie, two to four times per month. They use organic wastes for burning fire, eg, dry animal dung (manure), rather than wood or charcoal, as the fuel source (Figure 2). Our only inclusion criterion was screening the pulmonary functions in females who were exposed to biomass smoke. We had visits to the village and were able to screen 474 females who were exposed to biomass smoke. There are some conditions and comorbidities that may affect the pulmonary functions. Smoking is the leading cause of COPD; therefore, we eliminated females who were current or former smokers. Cardiovascular diseases are included in the comorbidities of COPD, and a volume overload due to heart failure or renal failure may affect PFT results negatively. Asthma is another important disease that results in altered PFT results; therefore, females who had history of allergy and asthma were excluded. Due to its inflammatory process, respiratory tract infection may narrow the airways with secretions and may affect PFT results, and hence those who received therapy due to upper or lower respiratory infections in the last 1 month were excluded. The final study group comprised 115 females who were purely exposed to biomass smoke (Table 1). A control group was generated with 73 healthy individuals who lived in the same area and

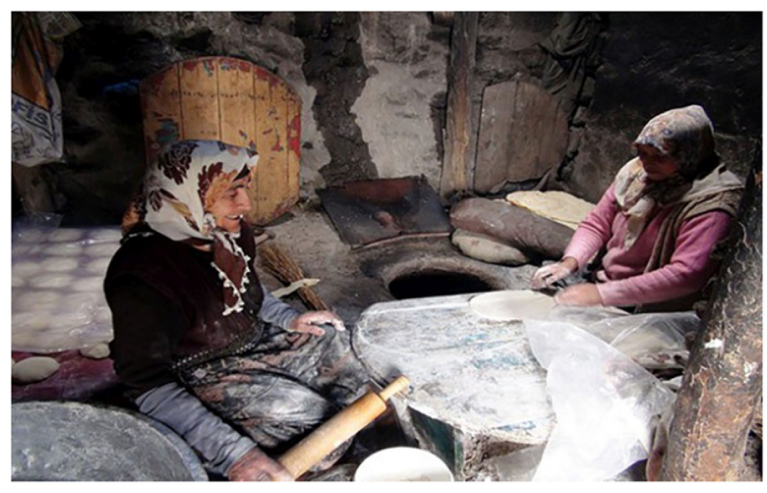

Figure I People are exposed to heavy smoke due to the cooking conditions (lack of chimney and poor ventilation).

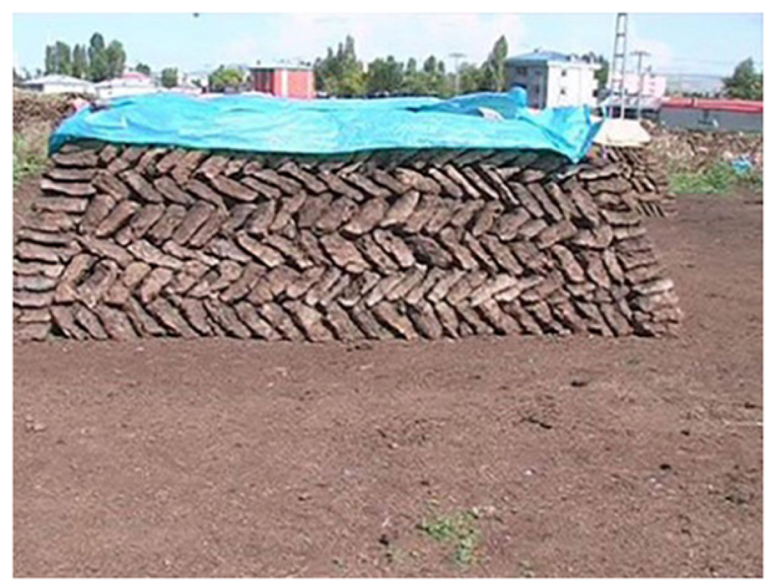

Figure 2 Dry animal dung (manure), rather than wood or charcoal, is used as the fuel source.

had never been exposed to biomass smoke. Both groups were matched according to age and body mass index.

All the research procedures were approved by the local ethical committee of the Public Health Directorship in Kars, and all participants provided written consent for the study. A PFT device (Spirolab III; MIR, Waukesha, WI, USA) was used on each patient after being calibrated by the technician, and forced expiratory volume in 1 second $\left(\mathrm{FEV}_{1}\right)$, forced vital capacity (FVC), and forced expiratory flow during the $25 \%-75 \%$ portion of the FVC (FEF 25-75) were recorded for both the study group and control group. PFT results were grouped in accordance with the guidelines of the European Respiratory Society and American Thoracic Society. ${ }^{7}$ FEF $25-75<60 \%$ was accepted as small airway, $\mathrm{FEV}_{1} / \mathrm{FVC}$ $<70 \%$ was accepted as obstructive, and $\mathrm{FEV}_{1} / \mathrm{FVC}>70 \%$ plus FVC $<80 \%$ was accepted as restrictive lung disease. After PFTs were performed in the study group and control group, the differences between the PFT results were evaluated. In addition, the age at which the participants started to cook and hours per day, weeks per month, and total years of cooking were questioned. These variables correlated with the PFT results in the study group. The risk of duration in years for existence of pathologic PFT results was calculated. In addition, we tried to formulate an index (CEI) like cigarette

Table I Demographic properties of the females eliminated from the study

\begin{tabular}{lll}
\hline & $\mathbf{n}$ & $\%$ \\
\hline Smokers (current/former) & 176 & 49 \\
Pneumonia, upper respiratory tract infection & 65 & 18 \\
Allergic asthma/rhinitis & 55 & 15 \\
Cardiovascular disease & 35 & 10 \\
Chronic renal failure & 28 & 8 \\
Total & 359 & 100 \\
\hline
\end{tabular}


pack year to provide data for intensity of biomass exposure. This index was defined by multiplying the duration of biomass exposure (in years) with the frequency of exposure (hours per day, weeks per month) and dividing the result by three. Finally, the correlation between CEI and pathologic PFT results was defined.

$\mathrm{CEI}=\frac{\text { Hours per day } \times \text { Weeks per month } \times \text { Exposure duration in year }}{3}$

\section{Statistical analysis}

Statistical Package for the Social Sciences 21.0 (IBM Corporation, Armonk, NY, USA) and MedCalc statistical software (MedCalc Software, Ostend, Belgium) were used for statistical analysis. Descriptive statistics (frequency, percentage, mean [min-max]) were used to evaluate the study data. The independent sample $t$-test was used to compare parameters between the groups. A one-way analysis of variance test was used to compare the parameters between more than one group, and the Bonferroni test was used to determine the group that showed significant difference. Pearson's correlation analysis was used to evaluate the relationship between PFT and independent variables (age, body mass index, age of starting cooking and hours per day, weeks per month, and years spent cooking). In addition, linear regression analyses were performed to evaluate the correlation between independent variables and PFT results. A receiver operating characteristic (ROC) curve analysis was performed to determine cutoff levels for duration in years and CEI for the existence of altered PFT results (small airway disease, obstruction, and restriction); moreover, sensitivity and specificity were calculated based on the cutoff value.

\section{Results}

A total of 188 females were evaluated in this study, of whom 115 had been exposed to biomass smoke and 73 had had no exposure to biomass smoke. Table 2 shows the general

Table 2 PFT values of the study group and the control group

\begin{tabular}{|c|c|c|c|c|c|}
\hline & \multicolumn{2}{|c|}{ Study group } & \multicolumn{2}{|c|}{ Control group } & \multirow[t]{2}{*}{$P$-value } \\
\hline & Median & IQR & Median & IQR & \\
\hline Age (years) & 33.4 & $30-37$ & 32.6 & $22.5-44.5$ & 0.110 \\
\hline BMI $\left(\mathrm{kg} / \mathrm{m}^{2}\right)$ & 24.7 & $|8-3|$ & 24.5 & $17-32$ & 0.115 \\
\hline $\mathrm{FEV}_{1}(\%)$ & 78.0 & $71-82$ & 80.0 & $76-87.5$ & 0.023 \\
\hline FVC (\%) & 81.0 & $82-88$ & 84.0 & 79-89 & 0.036 \\
\hline $\mathrm{FEV}_{\mathrm{I}} / \mathrm{FVC}(\%)$ & 79.0 & $74-84$ & 84.0 & $80.5-86$ & 0.001 \\
\hline FEF 25-75 (\%) & 70.0 & $65-75$ & 77.0 & $72-79$ & 0.001 \\
\hline
\end{tabular}

Note: Bold indicates a $P$-value $<0.05$.

Abbreviations: PFT, pulmonary function test; IQR, interquartile range; BMI, body mass index; $\mathrm{FEV}_{\text {, }}$, forced expiratory volume in I second; FVC, forced vital capacity; FEF $25-75$, forced expiratory flow during the $25 \%-75 \%$ portion of the FVC. characteristics and PFTs of the participants. The females who had been exposed to smoke were older than those in the control group, $33.4 \pm 7$ years and $32.6 \pm 8$ years, respectively. The study group and controls were grouped according to their PFT results: small airway disease, obstruction, and restriction. The median FEF $25-75$ value was $70.0 \%$ in the study group and $77.0 \%$ in controls $(P<0.001)$. The median $\mathrm{FEV}_{1} / \mathrm{FVC}$ value was $79.0 \%$ in the study group and $84.0 \%$ in controls $(P<0.001)$. The median $\mathrm{FEV}_{1}$ value was $78.0 \%$ in the study group and $80 \%$ in controls $(P=0.024)$, and the median FVC value was $81.0 \%$ in the study group and $84.0 \%$ in controls ( $P=0.036$; Table 2 and Figure 3$)$.

Twenty-seven $(23.8 \%)$ females in the study group and four $(5.5 \%)$ in the control group had small airway disease. Females who were exposed to biomass smoke had a higher probability of having small airway disease than those who were not $\left(\chi^{2}=3.895, P=0.038\right)$. Twenty-two (19.1\%) females in the study group and ten $(13.7 \%)$ in the control group had obstruction $\left(\mathrm{FEV}_{1} / \mathrm{FVC}<70 \%\right)$. Although the probability of having obstruction was higher in females who were exposed to biomass smoke, it was not statistically significant $\left(\chi^{2}=0.933, P=0.223\right)$. Twenty $(17.3 \%)$ females who were exposed to biomass smoke had restriction compared with ten $(13 \%)$ in the control group $\left(\chi^{2}=0.982, P=0.189\right.$; Table 3$)$.

We also evaluated correlations between PFT results and some parameters such as age at starting to cook, how many hours per day and weeks per month spent cooking, and the duration of biomass exposure. The median values of the parameters for the patient group are shown in Table 4.

In the study group, 27 (23.8\%) females had small airway disease and $22(19 \%)$ had obstructive airway disease. Starting to make bread at younger age and more weeks and more years spent cooking were risk factors for the development of both small airway disease and obstructive airway disease, whereas hours per day spent cooking was not a risk factor (Table 5).

In the study group, $20(17 \%)$ of the females had restrictive pulmonary disease. When the parameters were evaluated in this group, it was observed that starting to cook at younger age, more hours per day, more weeks per month, and more years spent cooking were all risk factors for the development of restrictive lung disease (Table 5).

We also performed a correlation analysis between dependent $\left(\mathrm{FEV}_{1}, \mathrm{FEV}_{1} / \mathrm{FVC}, \mathrm{FVC}\right)$ and independent variables (age at starting to cook, hours per day, weeks per month, duration in years). For $\mathrm{FEV}_{1} / \mathrm{FVC}$, the correlation analysis was statistically significant for duration of exposure to biomass smoke; as the duration of biomass exposure increased, $\mathrm{FEV}_{1} / \mathrm{FVC}$ was negatively affected. For $\mathrm{FEV}_{1} / \mathrm{FVC}$, no correlation with 

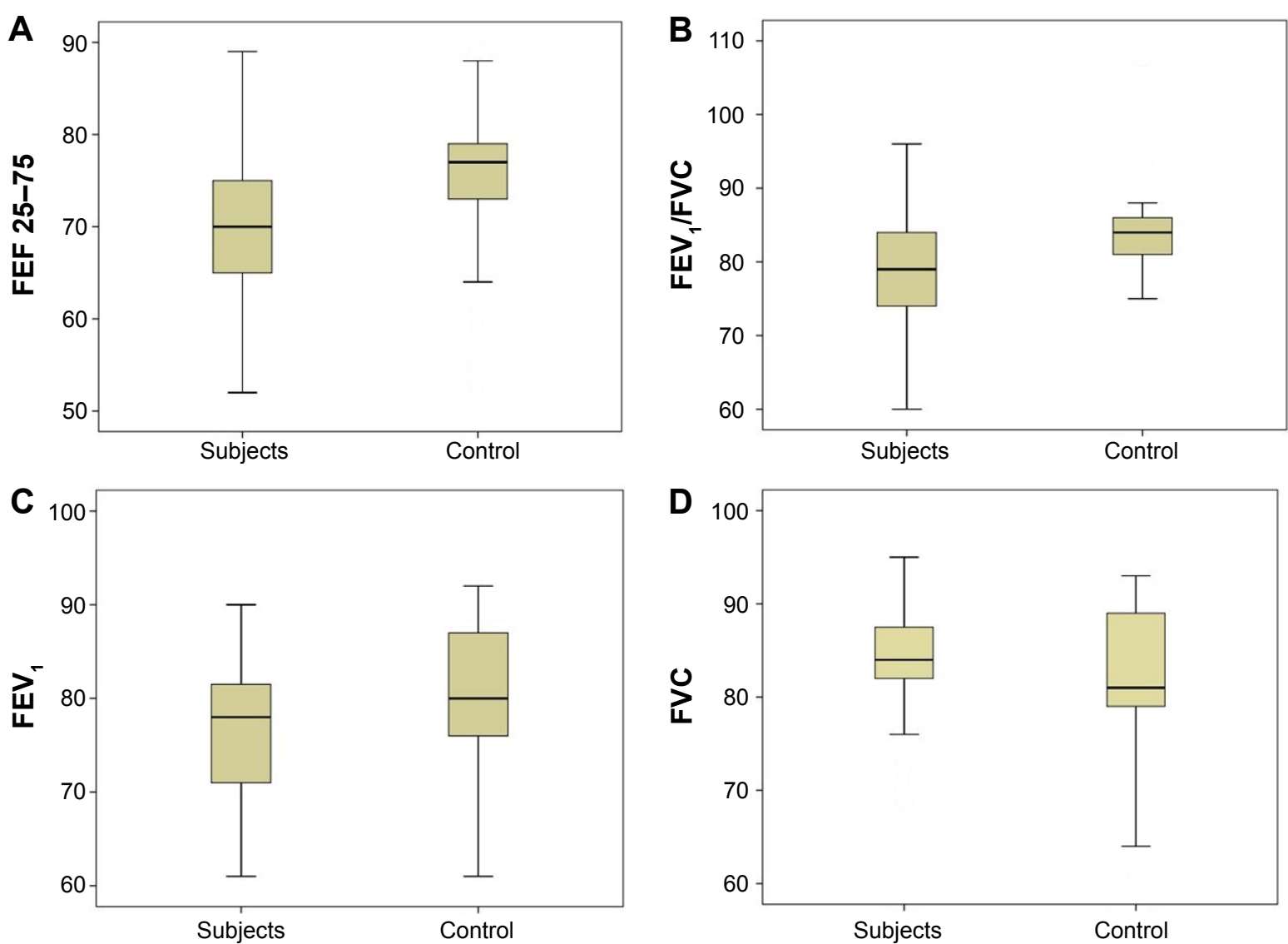

Figure 3 The difference of FEF 25-75 (A), FEV,/FVC (B), FEV (C), and FVC (D) results between the study group and control group.

Abbreviations: FEF $25-75$, forced expiratory flow during the $25 \%-75 \%$ portion of the FVC; FEV , forced expiratory volume in I second; FVC, forced vital capacity.

Table 3 Pathologic PFT results in the study group and control group

\begin{tabular}{llll}
\hline & $\begin{array}{l}\text { Study group, } \\
\mathbf{n}(\%)\end{array}$ & $\begin{array}{l}\text { Control group, } \\
\mathbf{n}(\%)\end{array}$ & P-value \\
\hline $\begin{array}{l}\text { Small airway disease } \\
\text { (FEF 25-75 }<60[\%])\end{array}$ & $27(23.4)$ & $4(5.5)$ & $\mathbf{0 . 0 3 8}$ \\
$\begin{array}{l}\text { Obstruction } \\
\text { (FEV,/FVC }<70[\%])\end{array}$ & $22(19.1)$ & $10(13.0)$ & 0.223 \\
$\begin{array}{l}\text { Restriction } \\
\text { (FEV } / \text { FVC }>70[\%],\end{array}$ & $20(17.3)$ & $10(13.0)$ & 0.189 \\
FVC $<80[\%])$ & & & \\
\hline
\end{tabular}

Note: Bold indicates a $P$-value $<0.05$.

Abbreviations: PFT, pulmonary function test; FEF 25-75, forced expiratory flow during the $25 \%-75 \%$ portion of the FVC; $\mathrm{FEV}_{1}$, forced expiratory volume in I second; FVC, forced vital capacity.

Table 4 Median values of the evaluated parameters in the study group $(\mathrm{N}=1 \mid 5)$

\begin{tabular}{llll}
\hline & Median & Min & Max \\
\hline Age (years) & 33.030 & 18 & 48 \\
Starting age (years) & 18.300 & 15 & 22 \\
Hours per day & 2.920 & 2 & 4 \\
Weeks per month & 2.500 & 1 & 4 \\
Duration (years) & 14.550 & 2 & 28 \\
\hline
\end{tabular}

Abbreviations: Min, minimum; Max, maximum.
Table 5 Determination of the risk factors for the altered PFT results

\begin{tabular}{|c|c|c|c|c|c|}
\hline & Mean & SD & Mean & SD & \multirow[t]{2}{*}{ P-value } \\
\hline & $>60(n=98)$ & FEF 25-75 & \multicolumn{2}{|c|}{ FEF 25-75 } & \\
\hline Starting age (years) & 18.480 & $1.85 \mathrm{I}$ & 17.290 & 1.724 & 0.015 \\
\hline Hours per day & 2.880 & 0.579 & 3.180 & 0.636 & 0.060 \\
\hline Weeks per month & 2.410 & 0.848 & 3.060 & 1.029 & 0.008 \\
\hline \multirow[t]{2}{*}{ Duration (years) } & 13.400 & 4.854 & 21.180 & 2.811 & 0.001 \\
\hline & \multicolumn{2}{|c|}{$\begin{array}{l}\text { FEV } / \text { IFV }>70 \\
(n=93)\end{array}$} & \multicolumn{2}{|c|}{$\begin{array}{l}\text { FEV }_{1} / F V C \leq 70 \\
(n=22)\end{array}$} & \\
\hline Starting age (years) & 18.510 & $1.85 \mathrm{I}$ & 17.450 & 1.765 & 0.018 \\
\hline Hours per day & 2.900 & 0.572 & 3.000 & 0.690 & 0.522 \\
\hline Weeks per month & 2.390 & 0.847 & 3.000 & 0.976 & 0.003 \\
\hline \multirow[t]{2}{*}{ Duration (years) } & 13.120 & 4.750 & 20.590 & 3.232 & 0.001 \\
\hline & $\begin{array}{l}\text { FEV }_{\mathbf{l}} / \mathrm{F} \\
>70, \mathrm{~F} \\
>80 \% \\
\end{array}$ & $\begin{array}{l}\text { C } \\
\text { C } \\
=95)\end{array}$ & $\begin{array}{l}\text { FEV }, \text { IF } \\
>70, \text { F } \\
<80 \% \\
\end{array}$ & $\begin{array}{l}C \\
C \\
=20)\end{array}$ & \\
\hline Starting age (years) & 18.400 & $\mathrm{I} .874$ & 17.300 & 1.636 & 0.048 \\
\hline Hours per day & 2.880 & 0.583 & 3.400 & 0.516 & 0.009 \\
\hline Weeks per month & 2.420 & 0.852 & 3.400 & 0.966 & 0.001 \\
\hline Duration (years) & 13.780 & 4.901 & 22.600 & 2.989 & 0.001 \\
\hline
\end{tabular}

Note: Bold indicates a $P$-value $<0.05$.

Abbreviations: PFT, pulmonary function test; SD, standard deviation; FEF 25-75, forced expiratory flow during the $25 \%-75 \%$ portion of the FVC; $\mathrm{FEV}_{1}$, forced expiratory volume in I second; FVC, forced vital capacity. 
Table 6 Correlation analysis between PFT results and independent variables in the study group

\begin{tabular}{cllll}
\hline & $\begin{array}{l}\text { Starting } \\
\text { age }\end{array}$ & $\begin{array}{l}\text { Hours } \\
\text { per day }\end{array}$ & $\begin{array}{l}\text { Weeks } \\
\text { per month }\end{array}$ & $\begin{array}{l}\text { Duration } \\
\text { (years) }\end{array}$ \\
\hline $\mathrm{FEV}_{1} / \mathrm{FVC}(\%)$ & & & & \\
$r$ & 0.067 & -0.106 & -0.074 & -0.488 \\
$P$ & 0.480 & 0.261 & 0.429 & $\mathbf{0 . 0 0 1}$ \\
$\mathrm{FEV}_{1}(\%)$ & & & & \\
$r$ & 0.270 & -0.172 & -0.194 & -0.749 \\
$P$ & $\mathbf{0 . 0 0 4}$ & 0.067 & $\mathbf{0 . 0 3 8}$ & $\mathbf{0 . 0 0 1}$ \\
$\mathrm{FVC} \mathrm{( \% )}$ & & & & \\
$r$ & 0.148 & -0.236 & -0.200 & -0.522 \\
$P$ & 0.114 & $\mathbf{0 . 0 1 1}$ & $\mathbf{0 . 0 3 2}$ & $\mathbf{0 . 0 0 1}$ \\
\hline
\end{tabular}

Note: Bold indicates a $P$-value $<0.05$.

Abbreviations: PFT, pulmonary function test; $\mathrm{FEV}_{1}$, forced expiratory volume in I second; FVC, forced vital capacity.

other independent variables was found. $\mathrm{FEV}_{1}$ was negatively correlated with weeks per month and duration in years. There was no correlation with starting age and hours per day for $\mathrm{FEV}_{1}$. Conversely, with the exception of age of starting to cook, a negative correlation with all the independent variables for FVC was found (Table 6).

By using the ROC curve analysis, we defined the duration for existence of small airway disease, obstruction, and restriction. The cutoff values were 16 years for small airway disease (sensitivity: 100\%, specificity: 76.9\%), 17 years for obstructive lung disease (sensitivity: $95.5 \%$, specificity: $69.9 \%$ ), and 17 years for restrictive lung disease (sensitivity: 100\%, specificity: 74.3\%; Figure 4).

The CEI was first defined by the present researchers in the literature. Females who had been exposed to biomass smoke and had altered PFT results had higher values of CEI compared with females who had PFT results with normal values (Table 7 and Figure 5). In addition, we calculated a cutoff value for pathologic PFT results using the ROC curve analysis. CEI was 34.7 for the existence of small airway disease, 42.7 for obstruction, and 45.3 for restriction (Table 8 and Figure 6).

\section{Discussion}

This case control study has two major findings: first, females who are exposed to biomass smoke are at risk of developing altered pulmonary function (both obstructive and restrictive lung disease), and second, the duration of exposure to biomass smoke is important for the probability of altered pulmonary function. In our study, both obstructive and restrictive lung diseases were observed among females who had been exposed to biomass smoke. Chronic exposure to smoke may cause inflammatory reactions in the alveolar space and the bronchial wall. ${ }^{8}$ As expected, this was the reason for obstructive lung disease in our patients. In our study, we observed that as biomass exposure increased in quantity and intensity, the risk of appearance of COPD increased. Similar results were reported in the studies by Ramírez-Venegas et $\mathrm{al}^{9}$ and Regalado et al. ${ }^{10}$ These authors reported that advanced stages of COPD exist as the duration of biomass smoke increases. According to our data, females who are exposed to biomass smoke for $>17$ years are at risk of developing COPD. In the current literature, the risk of developing obstructive airway disease usually requires $>20$ years of exposure..$^{9-11}$ The females in our study were exposed to more concentrated smoke because of the poor conditions in the places in which they cooked (Figure 1, no chimney and poor ventilation); massive smoke exposure may be the reason for altered PFT results of shorter duration.

In addition to obstruction, we also observed restrictive PFT results $\left(\mathrm{FEV}_{1} / \mathrm{FVC}>70, \mathrm{FVC}<80 \%\right)$ in $22(19.1 \%)$ females in the study group. In the current literature, a few studies mention a restrictive pattern in biomass exposure: Kara et $\mathrm{al}^{12}$ and Arslan et $\mathrm{al}^{13}$ defined restrictive images (opacities,
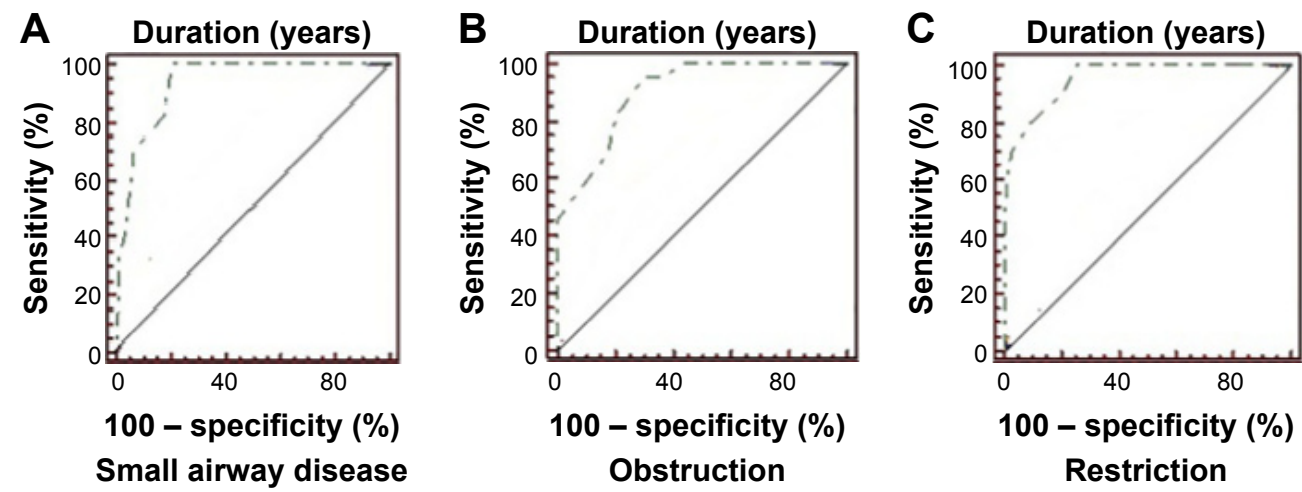

Figure 4 ROC curves of duration with small, obstructive, and restrictive airway diseases.

Notes: (A) ROC curve analysis for small airway disease (sensitivity, 100\%; specificity, 76.9\%). (B) ROC curve analysis for obstructive lung disease (sensitivity, $95.5 \%$; specificity, 69.9\%). (C) ROC curve analysis for restrictive lung disease (sensitivity, 100\%; specificity, 74.3\%).

Abbreviation: ROC, receiver operating characteristic. 
Table 7 Median values of CEl among biomass exposed women, who had altered and normal PFT results

\begin{tabular}{|c|c|c|c|}
\hline & $\mathbf{n}$ & Mean \pm SD & $P$-value \\
\hline Small airway disease & & & 0.001 \\
\hline FEF $25-75>60(\%)$ & 98 & $30.5 \pm 19.6$ & \\
\hline FEF $25-75<60$ (\%) & 27 & $65.5 \pm 35.2$ & \\
\hline Obstruction & & & 0.001 \\
\hline $\mathrm{FEV}_{\mathrm{I}} / \mathrm{FVC}>70(\%)$ & 93 & $31.4 \pm 20.6$ & \\
\hline $\mathrm{FEV}_{\mathrm{I}} / \mathrm{FVC}<70(\%)$ & 22 & $71.0 \pm 34.6$ & \\
\hline Restriction & & & 0.001 \\
\hline $\mathrm{FVC}>80(\%)$ & 95 & $32.4 \pm 21.2$ & \\
\hline FVC $<80(\%)$ & 20 & $87.6 \pm 30.9$ & \\
\hline
\end{tabular}

Abbreviations: CEl, cumulative exposure index; PFT, pulmonary function test; SD, standard deviation; FEF 25-75, forced expiratory flow during the $25 \%-75 \%$ portion of the FVC; FEV , forced expiratory volume in I second; FVC, forced vital capacity.
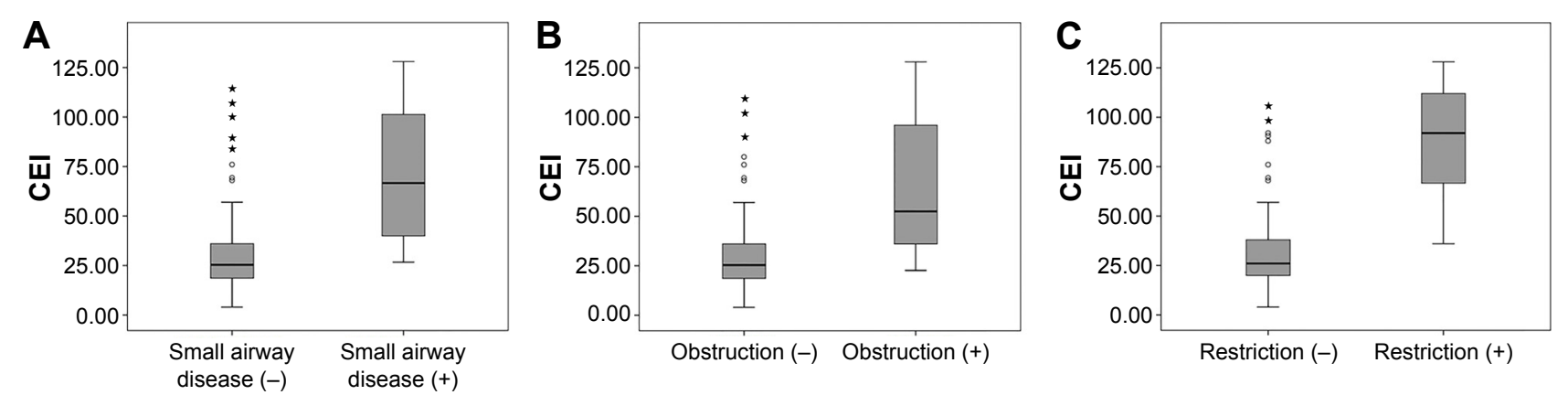

Figure 5 The difference of median values of CEl among all biomass exposed women based on PFT results.

Notes: The difference of $\mathrm{CEl}$ among all biomass exposed women with and without (A) small airway disease; (B) obstruction; and (C) restriction. Circles and stars indicate the cases out of $95 \% \mathrm{Cl}$.

Abbreviation: CEl, cumulative exposure index.

Table 8 Cutoff values of CEI for small airway disease, obstruction, and restriction

\begin{tabular}{lllllll}
\hline CEI & AUC & $\mathbf{9 5 \%} \mathbf{C l}$ & P-value & Cutoff & Sensitivity (\%) & Specificity (\%) \\
\hline Small airway disease & 0.876 & $0.802-0.930$ & $<0.001$ & 34.7 & 94.1 & 71.4 \\
Obstruction & 0.828 & $0.747-0.892$ & $<0.001$ & 42.7 & 63.6 & 86.0 \\
Restriction & 0.930 & $0.867-0.969$ & $<0.001$ & 45.3 & 90.0 & 84.8 \\
\hline
\end{tabular}

Abbreviations: $\mathrm{CEI}$, cumulative exposure index; $\mathrm{AUC}$, area under the curve; $\mathrm{Cl}$, confidence interval.
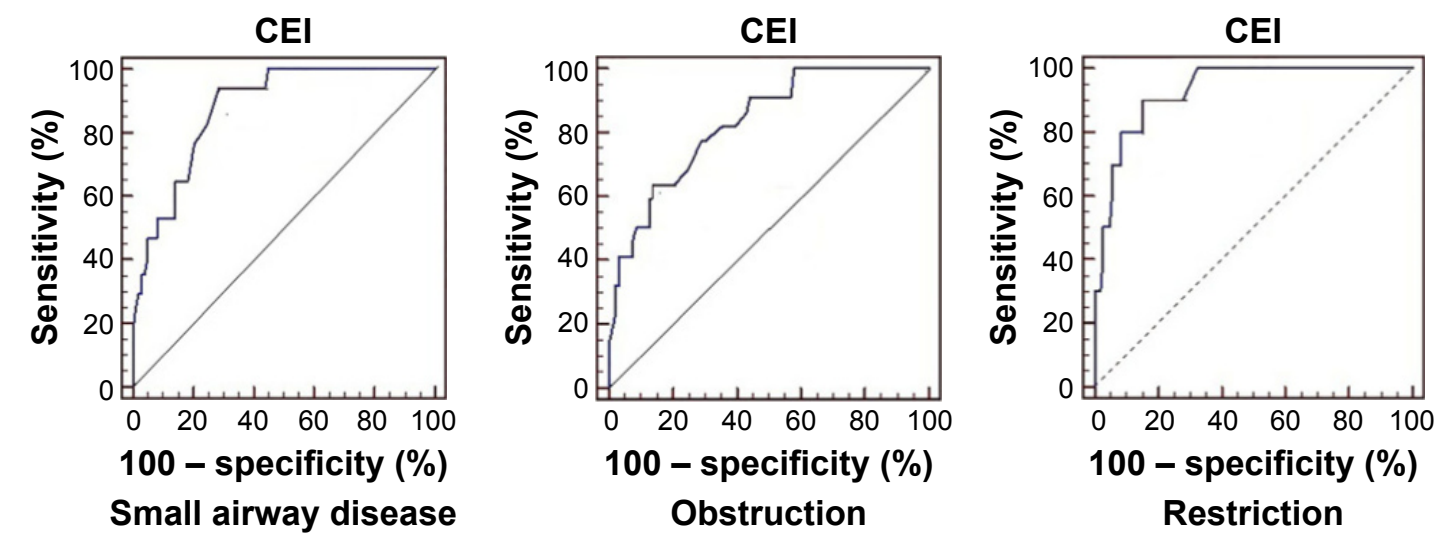

Figure 6 ROC curve analysis of CEl for small airway disease and obstructive and restrictive pulmonary diseases. Abbreviations: ROC, receiver operating characteristic; CEl, cumulative exposure index. 
fibrotic bands) in computed tomography (CT) scans of patients who were exposed to biomass smoke. Septal enlargements, goblet cell metaplasia, glandular hyperplasia, and fibrosis can be observed histopathologically when the source of energy is something other than wood. ${ }^{14}$ In our study, the restrictive results can be explained by the source of energy used by the females (females-burned animal waste [manure]; Figure 2). Burning organic material such as manure may cause some kind of chemical reactions, which may be responsible for restrictive lung disease. Although some studies have defined a correlation between restrictive lung disease and biomass exposure, none have mentioned the duration of exposure for the risk of developing restrictive lung disease. ${ }^{12,13}$ According to our data, females who are exposed to biomass smoke for $>17$ years are at risk of developing restrictive lung disease.

Twenty-seven (23.8\%) females had small airway disease. In our study, small airway disease was observed among females who started to cook at younger ages, and the duration of exposure for the risk of developing small airway disease was 16 years. The results of Rinne et $\mathrm{al}^{15}$ do not support our findings. They claimed that exposure to biomass smoke at younger ages was not a risk factor for small airway disease. There must be a reaction in distal airways for small airway disease to appear. Biomass fuel combustion produces particles sized $<10 \mu \mathrm{m}$. Particles $<10 \mu \mathrm{m}$ in diameter, particularly those $<2.5 \mu \mathrm{m}$, can penetrate deep into the lungs, especially into the peripheral airways. ${ }^{5,8}$

With the CEI calculation, we tried to define the importance of the intensity of biomass smoke. In this study, we did not accept exposure to biomass smoke to be like cigarette packet years. Cigarette smoke exhibits more homogeneous distribution compared with biomass smoke. Cigarette smokers smoke continuously, but the people in our study were exposed to biomass smoke for only a few hours per day, one day per week, or nearly every week. Pérez-Padilla et al ${ }^{16}$ and Ekici at al ${ }^{17}$ described a calculation by multiplying hours per day and total years; they defined that higher values from this calculation provided for greater probability of altered PFT results. The main difference of their study from ours was that the number of days per week that people were exposed to biomass smoke was not added to their calculation.

\section{Study limitations}

If it were possible to perform pulmonary imaging studies, particularly CT of the lungs, it would be possible to differentiate chronic bronchitis from emphysema and show reticulonodular appearance and fibrosis that could be suggestive for restrictive lung disease.

\section{Conclusion}

Biomass exposure is a very important public health problem among females, especially in developing countries. The risk of developing problems in lung functions begins after exposure to smoke for $>15$ years. Biomass smoke is responsible for both obstructive and restrictive pulmonary diseases. Precautions must be taken for populations living in these kinds of rural areas, and people must be educated about the adverse effects of biomass smoke.

\section{Acknowledgment}

The women pictured in Figure 1 gave their permission for their photograph to be published. The authors would like to thank the technician, Evren Cucu.

\section{Disclosure}

The authors report no conflicts of interest in this work.

\section{References}

1. de Koning HW, Smith KR, Last JM. Biomass fuel combustion and health. Bull World Health Organ. 1985;63(1):11-26.

2. Bruce N, Perez-Padilla R, Albalak R. Indoor air pollution in developing countries: a major environmental and public health challenge. Bull World Health Organ. 2000;78(9):1078-1092.

3. Salvi S, Barnes PJ. Is exposure to biomass smoke the biggest risk factor for COPD globally? Chest. 2010;138(1):3-6.

4. Torres-Duque C, Maldonado D, Pérez-Padilla R, Ezzati M, Viegi G; Forum of International Respiratory Studies (FIRS) Task Force on Health Effects of Biomass Exposure. Biomass fuels and respiratory diseases: a review of the evidence. Proc Am Thorac Soc. 2008;5(5):577-590.

5. Ezzati M, Kammen DM. The health impacts of exposure to indoor air pollution from solid fuels in developing countries: knowledge, gaps, and data needs. Environ Health Perspect. 2002;110(11):1057-1068.

6. Chen BH, Hong CJ, Pandey MR, Smith KR. Indoor air pollution in developing countries. World Health Stat Q. 1990;43(3):127-138.

7. Brusasco V, Crapo R, Viegi G. Coming together: the/ERS consensus on clinical pulmonary function testing. Eur Respir J. 2005;26(1):1-2.

8. Raj T JB. Altered lung function test in asymptomatic women using biomass fuel for cooking. J Clin Diagn Res. 2014;8(10):BC01-BC03.

9. Ramírez-Venegas A, Sansores RH, Quintana-Carrillo RH, et al. FEV1 decline in patients with chronic obstructive pulmonary disease associated with biomass exposure. Am J Respir Crit Care Med. 2014;190(9): 996-1002.

10. Regalado J, Pérez-Padilla R, Sansores R, et al. The effect of biomass burning on respiratory symptoms and lung function in rural Mexican women. Am J Respir Crit Care Med. 2006;174(8):901-905.

11. Døssing M, Khan J, al-Rabiah F. Risk factors for chronic obstructive lung disease in Saudi Arabia. Respir Med. 1994;88(7):519-522.

12. Kara M, Bulut S, Tas F, Akkurt I, Seyfikli Z. Evaluation of pulmonary changes due to biomass fuels using high-resolution computed tomography. Eur Radiol. 2003;13(10):2372-2377.

13. Arslan M, Akkurt I, Egilmez H, Atalar M, Salk I. Biomass exposure and the high resolution computed tomographic and spirometric findings. Eur J Radiol. 2004;52(2):192-199.

14. Mena MA, Woll F, Cok J, Ferrufino JC, Accinelli RA. Histopathological lung changes in children due to biomass fuel. Am J Respir Crit Care Med. 2012;185(6):687-688.

15. Rinne ST, Rodas EJ, Bender BS, et al. Relationship of pulmonary function among women and children to indoor air pollution from biomass use in rural Ecuador. Respir Med. 2006;100(7):1208-1215. 
16. Pérez-Padilla R, Regalado J, Vedal S, et al. Exposure to biomass smoke and chronic airway disease in Mexican women. A case-control study. Am J Respir Crit Care Med. 1996;154(3 pt 1):701-706.
17. Ekici A, Ekici M, Kurtipek E, et al. Obstructive airway diseases in women exposed to biomass smoke. Environ Res. 2005;99(1):93-98.

\section{Publish your work in this journal}

The International Journal of COPD is an international, peer-reviewed journal of therapeutics and pharmacology focusing on concise rapid reporting of clinical studies and reviews in COPD. Special focus is given to the pathophysiological processes underlying the disease, intervention programs, patient focused education, and self management protocols.
This journal is indexed on PubMed Central, MedLine and CAS. The manuscript management system is completely online and includes a very quick and fair peer-review system, which is all easy to use. Visit http://www.dovepress.com/testimonials.php to read real quotes from published authors. 